\title{
Frailty index is useful for predicting postoperative morbidity in older patients undergoing gastrointestinal surgery: a prospective cohort study
}

\author{
Chaoyang $\mathrm{Gu}^{\dagger}$, Anqing $\mathrm{Lu}^{\dagger}$, Chen $\mathrm{Lei}^{\dagger}$, Qingbin $\mathrm{Wu}^{\dagger}$, Xubing Zhang, Mingtian Wei and Ziqiang Wang
}

\begin{abstract}
Background: Many assessment tools have been used to identify frail surgical patients. This study was designed to explore the prediction value of the frailty index (FI) for postoperative morbidity in older patients undergoing elective gastrointestinal surgery.

Methods: Between January 2019 and September 2020, we conducted a prospective study in our hospital, and patients aged over 65 years were enrolled. The FI assessment was conducted by two specialist nurses based on the 38 -item scale, and patients were considered frail if the FI score was $\geq 0.25$. The primary outcome was 30 -day postoperative morbidity. Univariable and multivariable analyses were used to find the risk factors related to postoperative morbidity.
\end{abstract}

Results: A total of 246 consecutive patients were enrolled, for whom the median age was 72.0 [interquartile range (IQR): 67.0-77.0] years old, and 175 (71.1\%) were male. Of these, 47 (19.1\%) were frail. Patients with frailty were associated with older age $(p<0.001)$, higher American Society of Anesthesiologists (ASA) grade $(p=0.006)$, lower body mass index $(p=0.001)$, lower albumin $(p=0.003)$ and haemoglobin $(p<0.001)$ levels, increased blood loss $(p=0.034)$, increased risk of postoperative morbidity $(p<0.001)$, increased median length of stay $(p=0.017)$, and increased median postoperative hospital stay $(p=0.003)$. Multivariable analysis revealed that ASA grade [odds ratio (OR): 2.59 , 95\% confidence interval (CI) 1.19-5.64, $p=0.016]$, FI score (OR 7.68, 95\% Cl 3.19-18.48, $p<0.001)$ and surgical complexity (OR 22.83, 95\% Cl 5.46-95.51, $p<0.001)$ were independent predictors of 30-day postoperative morbidity. However, for patients with major surgery, FI score was the only independent predictor (OR 8.67, 95\% Cl 3.23-23.25, $p<0.001)$.

Conclusion: Frailty was associated with adverse perioperative outcomes, and the 38-item Fl scale was a useful frailty screening tool for older patients undergoing elective gastrointestinal surgery. For patients with major surgery, frailty was a more reliable predictor of postoperative 30-day morbidity than age and ASA grade.

Keywords: Older patients, Frailty index, Gastrointestinal surgery, Postoperative morbidity

*Correspondence: wangziqiang@scu.edu.cn

${ }^{\dagger}$ Chaoyang Gu, Anqing Lu, Chen Lei and Qingbin Wu have contributed equally to this article.

Department of Gastrointestinal Surgery, West China Hospital, Sichuan University, No. 37 Guo Xue Alley, Chengdu 610041, China

\section{Introduction}

Surgical treatment for older patients is increasingly prevalent as the older population is growing at an unprecedented rate. According to a systematic review of 70 studies, the prevalence of frailty in the older people 
undergoing general surgery ranged from $8 \%$ to $77.8 \%$ [1]. Frailty is commonly defined as a state of reduced physiologic capacity and increased susceptibility to disability caused by age-related loss of physical, cognitive, social, and psychological functions [2,3]. The older patients living with frailty have limited physiological reserve, hence, are susceptible to surgical stress. Therefore, 25\% to $50 \%$ postoperative adverse outcomes in older people were resulted from the concomitant frailty [4]. In addition, the presence of frailty before surgery was a strong and objective predictor of postoperative morbidity, mortality, discharge disposition, and health service resource utilisation for a variety of surgeries including gastrointestinal surgeries [1,5-13]. Consequently, it is increasingly important to assess the functional status and screen for frailty for older patients before surgery, because evidence for preoperative optimization showed prehabilitation and other modalities could improve the patients' reserve to cope with the stress of surgery [14].

There are two accepted paradigms of frailty: phenotypic construct, and deficit accumulation model. The phenotype construct is based on a cluster of signs and symptoms such as self-reported exhaustion, slowed performance (by walking speed), weakness (by grip strength), unintentional weight loss (4.5 kg in the past year), and low physical activity. The deficit accumulation model, contrarily, is quantified based on the number rather than the nature of health problems, along with biochemical and physiological impairments. An overlap exists between the two constructs, their sum contributing to a risk state [14]. The gold standard to define frailty in patients is based on the comprehensive geriatric assessment (CGA), which includes activities of daily living (ADL), physical, psychosocial, comorbidity, cognition state, and functional tests. However, CGA is time-consuming and needs professional geriatricians. Therefore, many other instruments had been developed to assess frailty, the Fried Phenotype and its modifications were most prevalent, followed by the clinical frailty scale (CFS), and a physical measure of frailty (gait speed, timed get up and go, handgrip strength, short physical performance battery). However, Fried Phenotype and physical measure of frailty were more concentrated on physical conditions, and CFS was too subjective. Nevertheless, frailty index (FI) scale basing on the accumulation of deficits, was an objective and clinically practical tool that was also commonly used [1]. FI scale also had many versions, such as Groningen Frailty Indicator (15 items) [15], G-8 (8 items) [16], and the latest and shortest version consisted of only 5 comorbidities (mFI-5) [17].

In 2008, Searle et al. developed a standard procedure for FI assessment with 40 items, and it had been simplified to 38 items by Munster et al.[18, 19]. However, this scale had never been used in elective gastrointestinal surgery. Therefore, we decided to conduct a prospective study to explore the value of this FI scale in predicting postoperative morbidity for older patients undergoing gastrointestinal surgery.

\section{Materials and methods Study population}

From January 2019 to September 2020, patients aged over 65 years and undergoing elective gastrointestinal surgery in the Department of Gastrointestinal Surgery, West China Hospital, Sichuan University, were prospectively enrolled. This study was approved by the ethics committee of our hospital [Approval number: 2019 (160)] and had registered in Clinicaltrails.gov (NCT03930082). Written informed consent was obtained from each participant, and this work was reported in line with the STROCSS criteria [20].

\section{Parameters measurement and frailty assessment}

Scale proposed by Searle SD et al. and modified by Munster et al. was used for FI assessment, which included 38 items consisting of ADL, comorbidity, physical, psychological, social, and cognitive items (Additional file 1: Table S1) $[18,19]$. The frailty assessment was completed within $6 \mathrm{~h}$ after admission. Firstly, the principal investigator interviewed every admitted patient, and relevant information, including comorbidity and mini-mental state examination (MMSE) scores were collected. Secondly, a specialist geriatric-trained nurse performed a series of function tests and completed the questionnaire (Additional file 1: Table S1) [18, 19]. Maximal grip strength was measured in the dominant hand using an electronic hand dynamometer. Walking speed (usual and rapid pace) was measured as the fastest time of two measurements. Five non-recordable grip strength and two missing walk time because of inability to walk were scored as positive items for frailty assessment. In addition, we also performed a set of function tests, however, similar to Munster et al., shoulder strength and peak flow measurement were excluded [19]. The FI was calculated by the proportion of positive items to all the 38 items. For the purposes of this study, we defined an FI score $<0.25$ as non-frail and a score of $\geq 0.25$ as frail [18].

\section{Data collection and outcomes}

C reactive protein (CRP), interleukin 6 (IL-6), albumin, and haemoglobin $(\mathrm{Hb})$ were tested and recorded within one week before surgery. Age, sex, body mass index (BMI), American Society of Anesthesiologists (ASA) grade were also recorded. In addition, we also collected operation time, blood loss, postoperative complications, postoperative intensive care unit (ICU) admission rate, 
30-day readmission, 30-day reoperation, length of hospital stay (LOS) and postoperative hospital stay (PHS). Postoperative complications were further defined using the Claviene-Dindo classification system. According to the surgical complexity, hernioplasty and laparoscopic exploratory biopsy were classified as minor surgery, while gastrectomy, colectomy, anterior resection (AR) for cancers in the stomach and colorectum were classified as major surgery.

The primary outcome was 30-day postoperative morbidity. Thus, we further explored the predicting value of the FI score in different complexity of surgeries.

\section{Statistical analysis}

Continuous variables were reported as median [interquartile range (IQR) $25-75 \%$ ], while categorical variables were shown as frequency and proportions. Chi-square $\left(x^{2}\right)$ test, independent $t$-test, and Wilcoxon rank-sum test were used to compare demographics and outcomes between different groups. $p$-value $<0.05$ was considered statistically significant. Correlation analysis was performed to explore the association between FI score and age. Univariable and multivariable logistic regression analyses were used to estimate the impact of frailty on postoperative morbidity, and odds ratio (OR) was calculated. To explore the impact of FI score on 30-day postoperative morbidity, Univariable and multivariable analyses were performed. To unify variable types for multivariable analyses, continuous variables such as age, blood loss, and operative time were divided into dichotomous variables by appropriate cutoff values. Finally, eight factors that could affect postoperative complications, including age, gender, FI score, ASA grade, surgical approach, surgical complexity, blood loss, and operative time were included in the analysis. Alpha was set at 0.05 and $95 \%$ confidence intervals (CIs) were reported. All statistical analyses were performed using SPSS, version 24 (IBM Corp., Armonk, NY).

\section{Results}

\section{Baseline characteristics and clinical outcomes}

A total of 276 patients were screened for eligibility, and 246 consecutive patients aged over 65 years were included in the analysis (Fig. 1). The median age was 72 (IQR 67.0-77.0) years old, and $175(71.1 \%)$ patients were male. Based on the FI score of $\geq 0.25,47$ patients (19.1\%) were frail. Correlation analysis showed that increasing correlated with the FI score $(p<0.001, \mathrm{r}=0.288$, Fig. 2$)$. Besides, frail patients had lower median BMI (23.4 vs $\left.22.1 \mathrm{~kg} / \mathrm{m}^{2}, p=0.005\right)$, lower median albumin level (41.1 40.2 g/L, $p=0.010)$, lower median Hb level (132 vs $118 \mathrm{~g} / \mathrm{L}, p<0.001$ ), and higher ASA grade (II vs III, $p=0.006)$ (Table 1$)$.
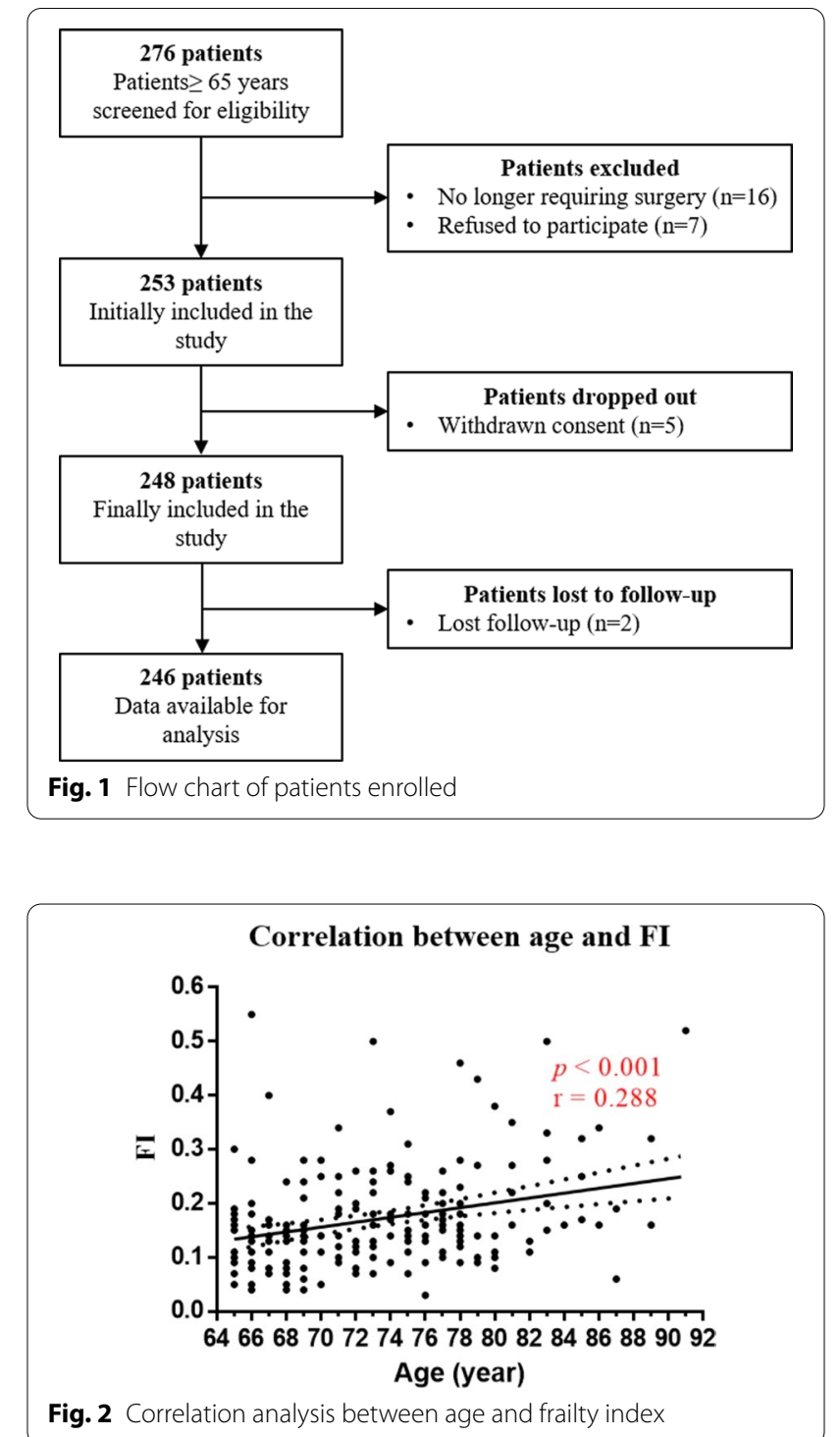

One hundred and six patients (43.1\%) underwent minor surgeries, and 140 patients (56.9\%) underwent major surgery (Table 2). Of the 106 patients with minor surgery, 95 (89.6\%) patients underwent hernioplasty, 11 (10.4\%) patients underwent laparoscopic exploratory biopsy (Additional file 1: Table S2). Among the 140 patients undergoing major surgery, 22 (15.7\%) underwent total gastrectomy, $9(6.4 \%)$ underwent distal gastrectomy, 4 (2.9\%) underwent proximal gastrectomy, 37 (26.4\%) underwent colectomy, and 68 (48.6\%) underwent anterior resection (AR) (Table 3).

Six patients $(2.4 \%)$ were admitted to ICU postoperatively, four patients were transferred to ICU for respiratory support due to difficulty in removing endotracheal intubation after operation, and two patients were 
Table 1 Patient baseline characteristics with or without frailty

\begin{tabular}{|c|c|c|c|c|}
\hline & No. of patients $(n=246)$ & Non-frail $(n=199)$ & Frail $(n=47)$ & $p$ \\
\hline Age $\left(\right.$ years) ${ }^{a}$ & $72(67.0-77.0)$ & $71.0(67.0-76.0)$ & $74.0(70.0-81.0)$ & 0.001 \\
\hline $\operatorname{Sex}(n, \%)$ & & & & 0.876 \\
\hline $\mathrm{F}$ & $71(28.9)$ & $57(28.6)$ & $14(29.8)$ & \\
\hline M & $175(71.1)$ & $142(71.4)$ & $33(70.2)$ & \\
\hline BMI $\left(\mathrm{kg} / \mathrm{m}^{2}\right)^{\mathrm{a}}$ & $23.4(20.8-25.1)$ & $23.4(21.2-25.3)$ & $22.1(19.9-24.3)$ & 0.005 \\
\hline Albumin $(\mathrm{g} / \mathrm{L})^{\mathrm{a}}$ & $40.9(38.7-43.3)$ & $41.1(39.3-43.4)$ & $40.2(37.6-42.2)$ & 0.010 \\
\hline $\mathrm{Hb}(\mathrm{g} / \mathrm{L})^{\mathrm{a}}$ & $130.5(115.0-140.3)$ & $132.0(118.0-143.0)$ & $118.0(96.0-113.0)$ & $<0.001$ \\
\hline $\operatorname{CRP}(\mathrm{g} / \mathrm{L})^{\mathrm{a}}$ & $3.6(2.3-7.3)$ & $3.8(2.4-6.7)$ & $3.3(2.1-26.8)$ & 0.712 \\
\hline IL-6 (ng/L) $)^{a}$ & $3.9(3.1-12.2)$ & $4.0(3.1-12.4)$ & $3.8(2.4-10.7)$ & 0.945 \\
\hline ASA grade $(n, \%)$ & & & & 0.006 \\
\hline$\|$ & $158(64.2)$ & $136(68.3)$ & $22(46.8)$ & \\
\hline III & $88(35.8)$ & $63(31.7)$ & $25(53.2)$ & \\
\hline
\end{tabular}

$B M I$ body mass index, $H b$ hemoglobin, $C R P$ C-reactive protein, IL- 6 interleukin-6, ASA American Society of Anesthesiologists

${ }^{a}$ Data showed as median (interquartile range $25-75 \%$ )

Table 2 Intra-and post-operative outcomes of all patients

\begin{tabular}{|c|c|c|c|c|}
\hline & No. of patients $(n=246)$ & Non-frail $(n=199)$ & Frail $(n=47)$ & $p$ \\
\hline Surgical approach (n, \%) & & & & 0.700 \\
\hline Open + converted & $183(74.4)$ & $147(73.9)$ & $36(76.6)$ & \\
\hline Laparoscopy & $63(25.6)$ & $52(26.1)$ & $22(23.4)$ & \\
\hline Surgical complexity (n, \%) & & & & 0.085 \\
\hline Minor $^{a}$ & $106(43.1)$ & $91(45.7)$ & $15(31.9)$ & \\
\hline Major $^{b}$ & $140(56.9)$ & $108(54.3)$ & $32(68.1)$ & \\
\hline Operative time $(\mathrm{min})^{c}$ & $147.5(44.0-210.0)$ & $137(40.0-200.0)$ & $170(60.0-240.0)$ & 0.105 \\
\hline Blood Loss $(\mathrm{ml})^{c}$ & $30.0(5.0-70.0)$ & $30.0(5.0-50.0)$ & $50.0(10.0-100.0)$ & 0.034 \\
\hline ICU admission (n, \%) & $6(2.4)$ & $3(1.5)$ & $3(6.4)$ & $0.086^{d}$ \\
\hline Morbidity (n, \%) & $59(24.0)$ & $32(16.1)$ & $27(57.4)$ & $<0.001$ \\
\hline Mortality (n, \%) & $2(0.8)$ & $1(0.5)$ & $1(2.1)$ & $0.346^{d}$ \\
\hline Readmission (n, \%) & $5(2.0)$ & $3(1.5)$ & $2(4.3)$ & $0.244^{d}$ \\
\hline Reoperation (n, \%) & $5(2.0)$ & $3(1.5)$ & $2(4.3)$ & $0.244^{d}$ \\
\hline $\operatorname{LOS}(\text { day })^{c}$ & $8.0(4.0-11.0)$ & $8.0(3.0-10.0)$ & $10.0(7.0-13.0)$ & 0.017 \\
\hline PHS (day) & $6.0(1.0-7.3)$ & $6.0(1.0-7.0)$ & $7.0(5.0-9.0)$ & 0.003 \\
\hline
\end{tabular}

${ }^{a}$ Hernioplasty and laparoscopic exploration biopsy

${ }^{b}$ Gastrectomy, colectomy, anterior resection (AR) for cancers in the stomach and colorectum

'Data showed as median (interquartile range 25-75\%)

${ }^{\mathrm{d}}$ Fisher exact test

transferred to ICU due to circulatory instability caused by anastomotic leakage and postoperative bleeding. Five patients $(2.0 \%)$ were readmitted following repeat surgery for complications. Of the five patients, three were due to anastomotic leakage, one was due to postoperative bleeding, and the other was due to incision dehiscence. A total of 81 complications occurred in 59 patients within 30 days postoperatively, most of those $(55 / 59,93.2 \%)$ were patients in major surgery group (Table 4). Postoperative complications were classified by the Clavien-Dindo scoring system, and did not demonstrate any differences in grade III and above complications between frail and non-frail patients $(6.4 \%[3 / 47]$ vs. $3.0 \%$ [6/199], $p=0.629)$ (Table 5).

\section{Association of frailty with overall intra-and post-operative} outcomes and who underwent major and minor surgery When compared to non-frail patients, patients with frailty were significantly associated with more median blood loss ( $30.0 \mathrm{ml}$ vs $50.0 \mathrm{ml}, p=0.034)$, higher postoperative morbidity $(16.1 \%$ vs $57.4 \%, p<0.001)$, longer 
Table 3 Intra-and post-operative outcomes of patients with major surgery

\begin{tabular}{|c|c|c|c|c|}
\hline & No. of patients $(n=140)$ & Non-frail $(n=108)$ & Frail $(n=32)$ & $p$ \\
\hline Surgical approach (n, \%) & & & & 0.150 \\
\hline Open + Converted & $90(64.3)$ & $66(61.1)$ & $24(75.0)$ & \\
\hline Laparoscopy & $50(35.7)$ & $42(38.9)$ & $8(25.0)$ & \\
\hline Procedure & & & & 0.020 \\
\hline Gastrectomy & $35(25.0)$ & $22(20.4)$ & $13(40.6)$ & \\
\hline Colectomy + AR & $105(75.0)$ & $86(79.6)$ & $19(59.4)$ & \\
\hline Operative Time $(\mathrm{min})^{\mathrm{a}}$ & $191.0(158.0-247.3)$ & $180.0(153.0-247.3)$ & $209.0(166.0-252.5)$ & 0.159 \\
\hline Blood Loss $(\mathrm{ml})^{\mathrm{a}}$ & $50.0(40.0-100.0)$ & $50.0(30.0-100.0)$ & $100.0(50.0-100.0)$ & 0.018 \\
\hline ICU admission (n, \%) & $6(4.3)$ & $3(2.8)$ & $3(9.4)$ & $0.132^{*}$ \\
\hline Morbidity (n, \%) & $55(39.3)$ & $30(27.8)$ & $25(78.1)$ & $<0.001$ \\
\hline Mortality (n, \%) & $2(1.4)$ & $1(0.9)$ & $1(3.1)$ & $0.406^{*}$ \\
\hline Readmission (n, \%) & $5(3.6)$ & $3(2.8)$ & $2(6.3)$ & $0.321^{*}$ \\
\hline Reoperation $(n, \%)$ & $5(3.6)$ & $3(2.8)$ & $2(6.3)$ & $0.321^{*}$ \\
\hline $\operatorname{LOS}(\text { day) })^{\mathrm{a}}$ & $10.0(8.3-13.0)$ & $10.0(8.0-12.0)$ & $11.0(10.0-16.0)$ & 0.032 \\
\hline PHS (day) $)^{a}$ & $7.0(6.0-9.0)$ & $7.0(6.0-8.0)$ & $9.0(7.0-12.8)$ & 0.001 \\
\hline
\end{tabular}

ICU intensive care unit, LOS length of hospital stay, PHS length of postoperative hospital stay, $A R$ anterior resection

${ }^{\text {a }}$ Data showed as median (interquartile range $25-75 \%$ )

*Fisher exact test

Table 4 Details of 30-day postoperative complications

\begin{tabular}{|c|c|c|c|}
\hline & No. of patients $(n=246)$ & Non-frail $(n=199)$ & Frail $(n=47)$ \\
\hline Postoperative pneumonia $(\mathrm{n}, \%)$ & $29(11.7)$ & $14(7.0)$ & $15(31.9)$ \\
\hline SSI (n, \%) & $13(5.3)$ & $8(4.0)$ & $5(10.6)$ \\
\hline $\mathrm{POI}(\mathrm{n}, \%)$ & $9(3.7)$ & $4(2.0)$ & $5(10.6)$ \\
\hline Anastomotic leakage $(n, \%)$ & $6(2.4)$ & $3(1.5)$ & $3(6.4)$ \\
\hline PRI (n, \%) & $5(2.0)$ & $3(1.5)$ & $2(4.3)$ \\
\hline Postoperative bleeding (n, \%) & $5(2.0)$ & $2(1.0)$ & $3(6.4)$ \\
\hline Urinary retention $(\mathrm{n}, \%)$ & $3(1.2)$ & $2(1.0)$ & $1(2.1)$ \\
\hline $\mathrm{DVT}(\mathrm{n}, \%)$ & $2(0.8)$ & $1(0.5)$ & $1(2.1)$ \\
\hline Cardiac-cerebral vascular events (n, \%) & $2(0.8)$ & $0(0)$ & $2(4.3)$ \\
\hline Other $(n, \%)$ & $7(2.8)$ & $5(2.5)$ & $2(4.3)$ \\
\hline Total $(n, \%)^{*}$ & $59(23.9)$ & $32(16.1)$ & $27(57.4)$ \\
\hline
\end{tabular}

SSI surgical site infection, $P O I$ postoperative ileus, $P R /$ progressive renal insufficiency; $D V T$ deep venous thrombosis

${ }^{*}$ A total of 81 complications occurred in 59 patients

Table 5 Claviene-Dindo classification of postoperative complications

\begin{tabular}{lllll}
\hline & $\begin{array}{l}\text { No. of } \\
\text { patients } \\
(\mathbf{n}=\mathbf{2 4 6 )}\end{array}$ & Non-frail $(\mathbf{n}=\mathbf{1 9 9})$ & Frail $(\mathbf{n}=\mathbf{4 7 )}$ & $\boldsymbol{p}$ \\
\hline $\mid$ & $19(7.7)$ & $9(4.5)$ & $10(21.3)$ & 0.629 \\
$\|$ & $31(12.6)$ & $17(8.5)$ & $14(29.8)$ & \\
$\geq$ III & $9(3.7)$ & $6(3.0)$ & $3(6.4)$ & \\
\hline
\end{tabular}

median LOS (8.0 days vs 10.0 days, $p=0.017)$ and PHS (6.0 days vs 7.0 days, $p=0.003$ ) (Table 2 ).

Subgroup analysis showed that following major surgery, patients with frailty had higher median blood loss (50.0 ml vs $100.0 \mathrm{ml}, p=0.017)$, higher postoperative morbidity $(27.8 \%$ vs $78.1 \%, p<0.001)$, longer LOS (10.0 days vs 11.0 days, $p=0.032$ ) and PHS (7.0 days vs 9.0 days, $p=0.001)$. These were similar to overall 
analysis (Table 3). However, frailty was not associated with intra-and postoperative parameters for patients following minor surgery (Additional file 1: Table S2).

\section{Independent predictors analysis of 30-day postoperative morbidity}

Binary Univariable logistic regression analysis showed FI score (OR 7.05, 95\% CI 3.53-14.06, $p<0.001$ ), ASA grade (OR 3.05, 95\% CI 1.67-5.57, $p<0.001$ ), surgical complexity (OR 16.50, 95\% CI 5.75-47.39, $p<0.001$ ), operative time (OR 4.11, 95\% CI 2.22-7.58, $p<0.001$ ), and blood loss (OR 5.29, 95\% CI 2.76-10.12, $p<0.001$ ) were associated with postoperative morbidity. However, multivariable analysis identified the FI score, ASA grade, as well as surgical complexity, having the strongest association with postoperative morbidity (ORs, 7.677, 2.592 and 22.830, respectively; 95\% CIs, 3.19-18.48, 1.19-5.64 and 5.4695.51; $p<0.001, p=0.016$ and $p<0.001$ ) (Table 6).

The same analysis was also performed for patients with major surgery. Univariable analysis identified age (OR 2.66, 95\% CI 1.23-5.75, $p=0.013$ ), FI score (OR 9.29, 95\% CI 3.64-23.72, $p<0.001$ ), and ASA grade (OR 3.05,
95\% CI 1.50-6.21, $p=0.002)$ were associated with postoperative morbidity, while multivariable analysis found FI score was the only independent predictor (OR 8.669, 95\% CI 3.233-23.245, $p<0.001$ ) (Table 7).

\section{Discussion}

To our best knowledge, this was the first study which prospectively validated the effectiveness of FI (38 items) in older patients undergoing elective gastrointestinal surgery. In this study, we found frailty was associated with older age, lower BMI, lower ALB and Hb level, and higher ASA grade. In addition, patients with frailty also had more intra-operative blood loss, higher incidence of postoperative complications, longer LOS and PHS. Moreover, the result of multivariable analysis for postoperative morbidity indicated that frailty assessed by 38-item FI scale was a more reliable predictor than age and ASA grade.

As expected, FI score increased steadily with age, as showed in Fig. 1, however, the small $r$ value (0.288) did not indicate a strong correlation between age and FI score as frailty was a state of pathological aging, and

Table 6 Univariable and multivariable logistic regression analysis of all patients for morbidity

\begin{tabular}{|c|c|c|c|c|c|c|}
\hline \multirow[t]{2}{*}{ Variables } & \multicolumn{3}{|c|}{ Univariable $(n=246)$} & \multicolumn{3}{|c|}{ Multivariable $(n=246)$} \\
\hline & OR & $95 \% \mathrm{Cl}$ & $p$ value & OR & $95 \% \mathrm{Cl}$ & $p$ value \\
\hline Gender (male vs female) & 0.60 & $0.32-1.11$ & 0.101 & 0.79 & $0.36-1.72$ & 0.548 \\
\hline Age $(\geq 75$ vs $<75)$ & 1.17 & $0.64-2.14$ & 0.607 & 1.573 & $0.67-3.69$ & 0.298 \\
\hline FI score (Frail vs Non-frail) & 7.05 & $3.53-14.06$ & $<0.001$ & 7.677 & $3.19-18.48$ & $<0.001$ \\
\hline ASA grade (III vs II) & 3.05 & $1.67-5.57$ & $<0.001$ & 2.592 & $1.19-5.64$ & 0.016 \\
\hline Surgical approach (laparoscopic vs open) & 1.24 & $0.65-2.39$ & 0.518 & 0.905 & $0.37-2.23$ & 0.827 \\
\hline Surgical complexity (major vs minor) & 16.50 & $5.75-47.39$ & $<0.001$ & 22.830 & $5.46-95.51$ & $<0.001$ \\
\hline Operative time ( $\geq 180 \mathrm{~min} v \mathrm{~s}<180 \mathrm{~min}$ ) & 4.11 & $2.22-7.58$ & $<0.001$ & 0.997 & $0.42-2.38$ & 0.994 \\
\hline Blood loss $(\geq 50 \mathrm{ml}$ vs $<50 \mathrm{ml})$ & 5.29 & $2.76-10.12$ & $<0.001$ & 1.121 & $0.41-3.09$ & 0.825 \\
\hline
\end{tabular}

Table 7 Univariable and multivariable logistic regression analysis of patients with major operations for morbidity

\begin{tabular}{|c|c|c|c|c|c|c|}
\hline \multirow[t]{2}{*}{ Variables } & \multicolumn{3}{|c|}{ Univariable $(n=140)$} & \multicolumn{3}{|c|}{ Multivariable $(n=140)$} \\
\hline & OR & $95 \% \mathrm{Cl}$ & $p$ value & OR & $95 \% \mathrm{Cl}$ & $p$ value \\
\hline Gender (male vs female) & 0.88 & $0.44-1.78$ & 0.729 & 0.86 & $0.38-1.99$ & 0.730 \\
\hline Age $(\geq 75$ vs $<75)$ & 2.66 & $1.23-5.75$ & 0.013 & 2.03 & $0.82-5.05$ & 0.129 \\
\hline FI score (Frail VS Non-frail) & 9.29 & $3.64-23.72$ & $<0.001$ & 8.67 & $3.23-23.25$ & $<0.001$ \\
\hline ASA grade (III VS II) & 3.05 & $1.50-6.21$ & 0.002 & 2.27 & $0.98-5.25$ & 0.055 \\
\hline Surgical approach (laparoscopic vs open) & 0.71 & $0.34-1.45$ & 0.341 & 0.93 & $0.37-2.34$ & 0.817 \\
\hline Operative time ( $\geq 180 \mathrm{~min}$ vs $<180 \mathrm{~min}$ ) & 1.56 & $0.78-3.12$ & 0.213 & 1.11 & $0.45-2.72$ & 0.825 \\
\hline Blood loss ( $\geq 50 \mathrm{ml} \mathrm{vs<50} \mathrm{ml)}$ & 1.59 & $0.74-3.43$ & 0.239 & 0.94 & $0.32-2.72$ & 0.907 \\
\hline
\end{tabular}

OR odds ratio, $\mathrm{Cl}$ confidence interval, $\mathrm{FI}$ frailty index, ASA American Society of Anesthesiologists 
aging alone was not equal to frailty [21]. Frailty was also associated with a low-grade chronic pro-inflammatory state characterised by increased levels of CRP and IL-6, and could further result in anaemia [22-24]. Although there was no difference in CRP and IL-6 levels between the frail and non-frail groups in this study, frailty was significantly associated with a lower $\mathrm{Hb}$ level $(p<0.001)$.

Previous studies demonstrated patients with frailty were associated with adverse postoperative outcomes, including a higher incidence of morbidity, mortality, and ICU admission across surgical specialties [10, 13, 25-30]. In our study, although there was no significant difference between frail and non-frail patients regardless of overall analysis or subgroup analysis for major surgery, the ICU admission rate and mortality of frail patients were higher than non-frail patients. Moreover, the incidence of 30-day postoperative complications in patients with frailty was significantly higher than that in nonfrail patients $(57.1 \%$ vs $16.1 \%, \mathrm{p}<0.001)$. In addition, for patients with major surgery, multivariable analysis identified that only FI independently predicted postoperative morbidity, suggesting that frailty assessed by 38 -item FI was a more reliable predictor than age and ASA grade, which was supported by Miller et al. [31].

A meta-analysis for patients with general surgery showed frail patients had a longer LOS than non-frail patients (9.6 vs 6.4 days, $95 \%$ CI $6.2-12.9$ ) [32]. In a prospective study in patients who followed a standardised enhanced recovery pathway, Keller et al. demonstrated a strong association between longer LOS and frailty [33]. Our study demonstrated similar findings of longer median LOS and PHS in frail patients.

There was no doubt that recovery after major surgery will need more physiological reserve and it was challenging for older patients. The 38-item FI score could therefore help in categorising older patients requiring major surgery into different risk groups in terms of 30-day postoperative morbidity, LOS, and PHS. Although the 38-item FI was not associated with any perioperative adverse events in patients requiring minor surgery, the incidence of adverse events in patients with minor surgery was fairly low (3.8\%). We believe that more subjects are probably needed to verify the effectiveness of 38-item FI in this group of patients in the future. In addition, these results also indicate that more sensitive assessment tools are needed for patients with minor gastrointestinal surgery because high sensitivity ensures frail patients can be correctly screened out [34].

Previous studies showed that preoperative prevention could reduce postoperative complications, preoperative exercise, management of comorbidity and nutrition could improve the postoperative outcomes of older patients [35-37]. Therefore, the 38-item FI scale could be used preoperatively to modify practice and potentially improve outcomes. It could be a useful tool for screening patients with frailty who need preoperative prevention, given that FI score was associated with adverse postoperative outcomes and was reliable for predicting complications. In addition, it was also helpful for preoperative informed consent and better allocated of postoperative support. In our institution, the FI score is now calculated in all elective cases. For those frail patients, the multidisciplinary care team can preemptively arrange postoperative nursing care, physical therapy, social work, and discharge disposition. Thus, a different clinical pathway may be more appropriate for frail patients. We believe there is potential to improve postoperative outcomes. Future prospective studies are needed to evaluate the implementation and outcomes of these altered pathways.

There are several limitations in the present study. Patients enrolled in the cohort mixed major and minor gastrointestinal surgeries, which had different incidences of postoperative adverse events. Nevertheless, subgroup analysis for patients with major surgery also revealed a clear correlation between FI score and postoperative adverse outcomes. Furthermore, the present study is a single-centre study with a small sample size, which also limits the validation efficiency for 38-item FI scale. In addition, the 38 -item FI scale treat cancer as a positive item which would inevitably lead to higher FI score in patients with cancers. Finally, frailty assessment by this scale is more time-consuming, so it is not suitable for emergency and outpatient patients. However, for inpatients preparing for surgery, it is worthwhile to use this scale for a comprehensive assessment. Further studies are needed to verify its superiority before its generalization.

\section{Conclusion}

Frailty was associated with adverse postoperative outcomes, and FI scale (38 items) is a useful tool for screening out frail patients from older patients undergoing elective gastrointestinal surgery. Our study also demonstrate that frailty has a robust impact on postoperative morbidity. Moreover, for patients with major gastrointestinal surgery, the FI score is a more reliable predictor of postoperative morbidity than age and ASA grade.

\section{Abbreviations}

CGA: Comprehensive geriatric assessment; ADL: Activities of daily living; CFS: Clinical Frailty Scale; Fl: Frailty index; MMSE: Mini-mental state examination; CRP: C reactive protein; IL-6: Interleukin 6; Hb: Haemoglobin; BMI: Body mass index; ASA: American Society of Anesthesiologists; ICU: Intensive care unit: LOS: Length of hospital stay; PHS: Length of postoperative hospital stay; AR: Anterior resection; IQR: Interquartile range; OR: Odds ratio; HR: Hazard ratio; Cl: Confidence interval. 


\section{Supplementary Information}

The online version contains supplementary material available at https://doi. org/10.1186/s12893-022-01471-9.

Additional file 1: Table S1. Frailty index scale (38 items). Table S2. Intraand post-operative outcomes of patients with minor surgery.

\section{Acknowledgements}

None.

\section{Authors' contributions}

Study concepts and design: CG, QW, and ZW; Data acquisition and follow-up: $A L, C L, C G, X Z$, and MW; Statistical analysis: CG, AL, CL, and QW; Manuscript preparation: $C G, A L$, and $C L$; Manuscript editing: $C G$, $Q W$, and $X Z$. All authors carefully reviewed the manuscript and approved the final version.

\section{Funding}

This work was supported by the Ministry of Science and Technology of the People's Republic of China (2017YFC0908204 to Ziqiang Wang), Department of Science and Technology of Sichuan Province (2019YFS0375 to Ziqiang Wang), and 1.3.5 project for disciplines of excellence-Clinical Research Incubation Project, West China Hospital, Sichuan University (2019HXFH031 to Ziqiang Wang).

\section{Availability of data and materials}

The data used and analyzed during the current study are available from the corresponding author on reasonable request.

\section{Declarations}

\section{Ethics approval and consent to participate}

This study was approved by the Ethic Committee of West China Hospital [Approval number: 2019 (160)] and written informed consent was obtained from all participants.

\section{Consent for publication}

Not Applicable.

\section{Competing interests}

The authors declare no competing interests.

Received: 30 March 2021 Accepted: 5 January 2022

Published online: 16 February 2022

\section{References}

1. Aucoin SD, Hao M, Sohi R, Shaw J, Bentov I, Walker D, et al. Accuracy and feasibility of clinically applied frailty instruments before surgery: a systematic review and meta-analysis. Anesthesiology. 2020;133(1):78-95.

2. Fried LP, Tangen CM, Walston J, Newman AB, Hirsch C, Gottdiener J, et al. Frailty in older adults: evidence for a phenotype. J Gerontol A Biol Sci Med Sci. 2001;56(3):M146-56

3. Rockwood K, Song X, Macknight C, Bergman H, Hogan DB, McDowell I, et al. A global clinical measure of fitness and frailty in elderly people. CMAJ. 2005;173(5):489-95.

4. Mclsaac DI, Jen T, Mookerji N, Patel A, Lalu MM. Interventions to improve the outcomes of frail people having surgery: a systematic review. PLoS ONE. 2017;12(12):e0190071.

5. Lin H-S, Watts JN, Peel NM, Hubbard RE. Frailty and post-operative outcomes in older surgical patients: a systematic review. BMC Geriatr. 2016;16(1):157.

6. Robinson TN, Eiseman B, Wallace J, Church SD, McFann KK, Pfister SM, et al. Redefining geriatric preoperative assessment using frailty, disability and co-morbidity. Ann Surg. 2009;250(3):449-55.

7. Robinson TN, Wu DS, Stiegmann GV, Moss M. Frailty predicts increased hospital and 6-month healthcare cost following colorectal surgery in older adults. Am J Surg. 2011;202(5):511-4.
8. Wilkes JG, Evans JL, Prato BS, Hess SA, MacGillivray DC, Fitzgerald TL. Frailty cost: economic impact of frailty in the elective surgical patient. J Am Coll Surg. 2019;228(6):861-70.

9. Hewitt J, Carter B, Vilches-Moraga A, Quinn TJ, Braude P, Verduri A, et al. The effect of frailty on survival in patients with COVID-19 (COPE): a multicentre, European, observational cohort study. Lancet Public Health. 2020;5(8):e444-51.

10. Mclsaac DI, Taljaard M, Bryson GL, Beaulé PE, Gagné S, Hamilton G, et al. Frailty as a predictor of death or new disability after surgery: a prospective cohort study. Ann Surg. 2020;271(2):283-9.

11. Revenig LM, Canter DJ, Kim S, Liu Y, Sweeney JF, Sarmiento JM, et al. Report of a simplified frailty score predictive of short-term postoperative morbidity and mortality. J Am Coll Surg. 2015;220(5):904-11.

12. Buettner S, Wagner D, Kim Y, Margonis GA, Makary MA, Wilson A, et al. Inclusion of sarcopenia outperforms the modified frailty index in predicting 1-year mortality among 1,326 patients undergoing gastrointestinal surgery for a malignant indication. J Am Coll Surg. 2016;222(4):397-407.

13. Shen $Y$, Hao Q, Zhou J, Dong B. The impact of frailty and sarcopenia on postoperative outcomes in older patients undergoing gastrectomy surgery: a systematic review and meta-analysis. BMC Geriatr. 2017;17(1):188

14. Subramaniam A, Tiruvoipati R, Lodge M, Moran C, Srikanth V. Frailty in the older person undergoing elective surgery: a trigger for enhanced multidisciplinary management - a narrative review. ANZ J Surg. 2020;90(3):222-9.

15. Peters LL, Boter H, Buskens E, Slaets JP. Measurement properties of the Groningen frailty Indicator in home-dwelling and institutionalized elderly people. J Am Med Dir Assoc. 2012;13(6):546-51.

16. Bellera CA, Rainfray M, Mathoulin-Pelissier S, Mertens C, Delva F, Fonck $M$, et al. Screening older cancer patients: first evaluation of the $G-8$ geriatric screening tool. Ann Oncol. 2012;23(8):2166-72.

17. Subramaniam S, Aalberg JJ, Soriano RP, Divino CM. New 5-factor modified frailty index using American College of Surgeons NSQIP Data. J Am Coll Surg. 2018;226(2):173-181.e178.

18. Searle SD, Mitnitski A, Gahbauer EA, Gill TM, Rockwood K. A standard procedure for creating a frailty index. BMC Geriatr. 2008;8:24.

19. Munster BCV, Drost $D$, Kalf A, Vogtlander NP. Discriminative value of frailty screening instruments in end-stage renal disease. Clin Kidney J. 2016;9(4):606-10.

20. Agha R, Abdall-Razak A, Crossley E, Dowlut N, losifidis C, Mathew G, et al. STROCSS 2019 Guideline: strengthening the reporting of cohort studies in surgery. Int J Surg. 2019:72:156-65.

21. Beggs T, Sepehri A, Szwajcer A, Tangri N, Arora RC. Frailty and perioperative outcomes: a narrative review. Can J Anaesth. 2015;62(2):143-57.

22. Wilson D, Jackson T, Sapey E, Lord JM. Frailty and sarcopenia: the potential role of an aged immune system. Ageing Res Rev. 2017:36:1-10.

23. Tavenier J, Leng SX. Inflammatory pathways to anemia in the frail elderly. Clin Geriatr Med. 2019;35(3):339-48.

24. Leng S, Chaves P, Koenig K, Walston J. Serum interleukin- 6 and hemoglobin as physiological correlates in the geriatric syndrome of frailty: a pilot study. J Am Geriatr Soc. 2002;50(7):1268-71.

25. Panayi AC, Orkaby AR, Sakthivel D, Endo Y, Varon D, Roh D, et al. Impact of frailty on outcomes in surgical patients: a systematic review and metaanalysis. Am J Surg. 2019;218(2):393-400.

26. Saxton A, Velanovich V. Preoperative frailty and quality of life as predictors of postoperative complications. Ann Surg. 2011;253(6):1223-9.

27. Robinson TN, Wu DS, Pointer L, Dunn CL, Cleveland JC Jr, Moss M. Simple frailty score predicts postoperative complications across surgical specialties. Am J Surg. 2013;206(4):544-50

28. Kim S-W, Han H-S, Jung H-W, Kim K-I, Hwang DW, Kang S-B, et al. Multidimensional frailty score for the prediction of postoperative mortality risk. JAMA Surg. 2014;149(7):633-40.

29. Ruiz de Gopegui Miguelena P, Martínez Lamazares MT, Miguelena Hycka J, Claraco Vega LM, Gurpegui Puente M. Influence of frailty in the outcome of surgical patients over 70 years old with admission criteria in ICU. Cir Esp. 2020;99:41-8

30. Giannotti C, Sambuceti S, Signori A, Ballestrero A, Murialdo R, Romairone $\mathrm{E}$, et al. Frailty assessment in elective gastrointestinal oncogeriatric surgery: predictors of one-year mortality and functional status. J Geriatr Oncol. 2019;10(5):716-23. 
31. Miller SM, Wolf J, Katlic M, D'Adamo CR, Coleman J, Ahuja V. Frailty is a better predictor than age for outcomes in geriatric patients with rectal cancer undergoing proctectomy. Surgery. 2020;168(3):504-8.

32. Hewitt J, Long S, Carter B, Bach S, McCarthy K, Clegg A. The prevalence of frailty and its association with clinical outcomes in general surgery: a systematic review and meta-analysis. Age Ageing. 2018;47(6):793-800.

33. Keller DS, Bankwitz B, Nobel T, Delaney CP. Using frailty to predict who will fail early discharge after laparoscopic colorectal surgery with an established recovery pathway. Dis Colon Rectum. 2014:57(3):337-42.

34. Hamaker ME, Jonker JM, de Rooij SE, Vos AG, Smorenburg CH, van Munster $B C$. Frailty screening methods for predicting outcome of a comprehensive geriatric assessment in elderly patients with cancer: a systematic review. Lancet Oncol. 2012;13(10):e437-44.

35. Gillis C, Buhler K, Bresee L, Carli F, Gramlich L, Culos-Reed N, et al. Effects of nutritional prehabilitation, with and without exercise, on outcomes of patients who undergo colorectal surgery: a systematic review and metaanalysis. Gastroenterology. 2018;155(2):391-410.

36. Mende A, Riegel A-K, Plümer L, Olotu C, Goetz AE, Kiefmann R. Determinants of perioperative outcome in frail older patients. Dtsch Arztebl Int. 2019;116(5):73-82.

37. Gillis C, Li C, Lee L, Awasthi R, Augustin B, Gamsa A, et al. Prehabilitation versus rehabilitation: a randomized control trial in patients undergoing colorectal resection for cancer. Anesthesiology. 2014;121(5):937-47.

\section{Publisher's Note}

Springer Nature remains neutral with regard to jurisdictional claims in published maps and institutional affiliations.

- fast, convenient online submission

- thorough peer review by experienced researchers in your field

- rapid publication on acceptance

- support for research data, including large and complex data types

- gold Open Access which fosters wider collaboration and increased citations

- maximum visibility for your research: over $100 \mathrm{M}$ website views per year

At BMC, research is always in progress.

Learn more biomedcentral.com/submissions 